\title{
Study of abnormal umbilical artery doppler and neonatal outcome
}

\author{
Gyawali Merina', Poudel Ramesh ${ }^{2}$ \\ ${ }^{1}$ Lecturer, ${ }^{2}$ Resident Department of Radiodiagnosis and Imaging. Manipal Teaching Hospital, Pokhara, Nepal.
}

Background: Doppler provides assessment of uteroplacental and fetoplacental circulation during pregnancy. It is a sensitive tool in early detection of fetal compromise and allows needful intervention. Aims and Objective: To study the role of umbilical artery doppler in clinically suspected IUGR and its implication on neonatal outcome. Materials and Methods: A total of 104 singleton pregnancies with gestational age of more than 34 weeks who had clinical suspicion of IUGR were evaluated using obstetric ultrasound and doppler. Umbilical artery velocimetry with $S / D>3$ and $\mathrm{RI}>0.7$ were considered abnormal. Newborns were classified as either small for gestational age (SGA) ie, IUGR or appropriate for gestational age (AGA). Neonatal outcome were classified as either normal or adverse events that included still birth, NICU admissions, perinatal asphyxia and/or neonatal death. Results: Out of 104 clinically suspected IUGR, 55 were born with small for gestational age. Among these SGA neonates, 45 subjects had abnormal umbilical artery S/D and 42 had abnormal RI. Abnormal umbilical artery S/D ratio had a sensitivity of $81.8 \%$, specificity of $59.2 \%$, the positive predictive value of $69.2 \%$ and negative predictive value of $74.4 \%$. Abnormal Umbilical artery RI had a sensitivity of $76.4 \%$, specificity of $69.4 \%$, positive predictive value of $73.7 \%$ and negative predictive value of $72.3 \%$ in diagnosing IUGR. Abnormal umbilical artery velocimetry was associated with increased morbidity and mortality in IUGR neonates. Conclusions: Umbilical artery doppler plays an important role in diagnosing IUGR and predicting neonatal outcome.

Key words: Doppler; Umbilical artery velocimetry; Intrauterine growth restriction; Small for gestational age; Neonate

\section{INTRODUCTION}

Ultrasonography is safe in pregnancy and hence can be repeated as and when indicated. Doppler velocimetry is a noninvasive method of indirectly assessing the uteroplacental and fetal circulation. ${ }^{1}$ It is a sensitive tool in early detection of fetal compromise. It can predict adverse perinatal outcome and can be utilized for timely intervention. ${ }^{2}$ Vascular and hemodynamic changes appear in the severely compromised fetus which are predictors of poor perinatal outcome. ${ }^{3}$ Several Doppler-derived indices of umbilical, uterine and middle cerebral arteries have been used to identify fetuses at risk of increased perinatal morbidity and mortality who may benefit from continuous surveillance or elective delivery. Umbilical artery Doppler waveform is one of the most frequently used noninvasive tests for fetal well-being. Umbilical artery velocimetry are beneficial in initial evaluation and follow up of high risk pregnancy cases like maternal hypertension, IUGR and pregnancy induced hypertension. ${ }^{4}$

Among them umbilical artery systolic/diastolic (S/D) ratio, resistance index $(\mathrm{RI})$ and pulsatility index $(\mathrm{PI})$ are the most common parameters used in clinical practice. ${ }^{5,6}$ Small for gestational age (SGA) fetuses are either constitutionally small fetuses or fetuses that have failed to achieve their growth potential (IUGR). ${ }^{7}$ Intrauterine growth restriction (IUGR) is a condition in which a fetus fails to achieve its growth potential and is consequently at a risk of increased perinatal morbidity and mortality. ${ }^{8}$ The timely clinical suspicion and diagnosis of IUGR via Doppler and abnormal umbilical velocimetry may help in preventing the possible perinatal complications, morbidity and mortality. ${ }^{9}$ The aim of the study is to describe the role of umbilical artery Doppler in clinically suspected IUGR and to predict the neonatal outcome. 


\section{MATERIALS AND METHODS}

This prospective, hospital based study was conducted in Department of Radiodiagnosis and Imaging in Manipal Teaching Hospital, Pokhara, Nepal. The study duration was of two years (January 2017 to December 2018). Patients with informed consent were selected with inclusion criteria of: 1. singleton pregnancy, 2. Gestational age of 34 weeks or more as confirmed with prior obstetric scan or as calculated from last menstrual period(LMP) and 3. clinically suspected IUGR. Whereas, subjects with uncertain gestational age \& LMP, multiple pregnancies, documented pregnancy with major congenital or chromosomal abnormality or both and maternal or fetal conditions requiring immediate hospitalization and intervention were the major exclusion criteria.

Cases included subjects referred to department of Radiodiagnosis and imaging suspected of IUGR. Detailed antenatal history along with previous obstetric ultrasound was collected from patients.

Obsteric scan along with doppler was done using LOGIQ P3 by Wipro GE System using $3 \mathrm{MHz}$ curvilinear transducer. A free loop of umbilical cord located between the abdominal wall and placental insertion was selected for umbilical artery doppler study. The indices used for measurement were umbilical artery waveform, RI and $\mathrm{S} / \mathrm{D}$ ratio. Umbilical artery velocimetry with $\mathrm{RI}>0.7$ and $\mathrm{S} / \mathrm{D}>3$ and in were considered abnormal.

Neonatal data were obtained within 24 hours of birth and based on Lubchenco chart, the newborns were classified as either small for gestational age (SGA) ie, IUGR or appropriate for gestational age (AGA). Neonatal outcome were classified as either normal or adverse events that included still birth, NICU admission, perinatal asphyxia and/or neonatal death.

A total of 116 patients with study eligibility were collected over a period of 2 years. However, 4 were lost to follow up, 5 were excluded because of uncertain LMP and gestational age and 3 were excluded because of inadequate data. Finally, a total of 104 patients were enrolled for study.

Data collected were entered in the Microsoft excel sheet. SPSS version 18 was used for statistical analysis. Ethical clearance was obtained from the institutional ethical clearance committee.

\section{RESULTS}

A total of 104 pregnant subjects with clinical suspicion of IUGR enrolled for the study. Forty six were primigravida and 58 were multigravida. Patients were aged between
18 and 38 years (average of 25 years). Sixteen out of $104(15.4 \%)$ subjects gave bad obstetric history. Twenty five percent subjects (26 out of 104) had history of pregnancy induced hypertension (PIH).

Average gestation age according to LMP was 36 weeks 6 days (range of 33 weeks 4 days to 40 weeks 2 days). Average gestation age of fetus derived by ultrasound measurement was 35 weeks 1 day (range of 31 weeks 1 day to 38 weeks 6 days).

Out of those 104 subjects with clinical suspicion of IUGR, 49 were born with appropriate for gestation age, whereas, 55 were born with small for gestation age and hence IUGR. AFI measurement ranged from $1.8 \mathrm{~cm}$ to $24.48 \mathrm{~cm}$ with average of $8.7 \mathrm{~cm}$. Twelve subjects had AFI less than $5 \mathrm{~cm}$ (Table 1).

The average expected fetal weight calculated by USG was 2345 grams (with a minimum weight of 1690 grams and maximum weight of 3420 grams). Doppler velocimetry included calculation of S/D ratio and RI of the umbilical artery. The various Doppler velocimetry findings of the umbilical artery are shown in Table 2 and 3.

Out of 104 foetuses, 55 were born with small for gestation age and 49 were appropriate for gestation age. Both S/D ratio and RI of umbilical artery were abnormal in foetuses with adverse outcome.

Umbilical artery S/D ratio $>3$ had a sensitivity of $81.8 \%$, specificity of $59.2 \%$, the positive predictive value of 69.2

\begin{tabular}{|c|c|c|}
\hline AFI & Frequency & Percentage \\
\hline$>10 \mathrm{cms}$ & 36 & 34.6 \\
\hline $5-10 \mathrm{cms}$ & 56 & 53.8 \\
\hline$<5 \mathrm{cms}$ & 12 & 11.6 \\
\hline
\end{tabular}

\begin{tabular}{|c|c|c|c|}
\hline $\begin{array}{l}\text { Umbilical Artery } \\
\text { S/D ratio }\end{array}$ & SGA $\%$ & AGA $\%$ & Total \% \\
\hline Abnormal (>3) & $45(81.8)$ & $20(40.8)$ & $65(62.5)$ \\
\hline Normal & $10(18.2)$ & $29(59.2)$ & 39 (37.5) \\
\hline Total & $55(100)$ & $49(100)$ & $104(100)$ \\
\hline
\end{tabular}

\begin{tabular}{|c|c|c|c|}
\hline $\begin{array}{l}\text { Umbilical Artery } \\
\text { RI }\end{array}$ & SGA $\%$ & AGA $\%$ & Total \% \\
\hline Abnormal (>0.7) & $42(76.4)$ & $15(30.6)$ & $57(54.8)$ \\
\hline Normal & $13(23.6)$ & $34(69.4)$ & $47(45.2)$ \\
\hline Total & $55(100)$ & $49(100)$ & $104(100)$ \\
\hline
\end{tabular}


$\%$ and negative predictive value of $74.4 \%$ in diagnosing IUGR. Abnormal Umbilical artery S/D ratio of more than 3 was observed in 65 out of 104 subjects. Six subjects had absent end diastolic flow (AEDF) and all these were found in SGA subjects. None of the subjects had reverse end diastolic flow (REDF).

Abnormal Umbilical artery RI was observed in 57 out of 104 subjects.Umbilical artery RI had a sensitivity of $76.4 \%$, specificity of $69.4 \%$, positive predictive value of $73.7 \%$ and negative predictive value of $72.3 \%$ in diagnosing IUGR.

Post Delivery/Neonatal Outcome: The average weight of the neonate at birth was $1.9 \mathrm{~kg}$ (range of $1.45 \mathrm{~kg}$ to $3.75 \mathrm{~kg}$ ). A total of 55 neonates $(52.8 \%)$ were born with small for gestation age (SGA). NICU admissions comprised of a total of twenty eight neonates.

Neonatal Outcome in SGA with Abnormal Umbilical Artery Doppler Studies: Out of 104 clinically suspected IUGR, $55(52.9 \%)$ were born with small for gestational age. Forty five had abnormal umbilical artery $\mathrm{S} / \mathrm{D}$ ratio and abnormal RI amongst 42. Forty out of 55 (72.7\%) neonate with SGA were delivered by LSCS. Twenty four out of $28(85.7 \%)$ had NICU admission. Nine developed perinatal asphyxia. Two had neonatal death within 1 week. There were 4 still born deaths among those with SGA.

\section{DISCUSSION}

In a study conducted in Thailand by Chanprapaph et al ${ }^{10}$ there were 212 clinically suspected IUGR, with gestational age between 30-42 weeks. The prevalence of IUGR was $50.9 \%$ which is comparable to our study percentage of $52.9 \%$. In another study conducted in 118 cases of high risk singleton pregnant women in China, the prevalence of IUGR in the study population was $16.9 \% .{ }^{11}$ In a study by Ghosh GS et al. ${ }^{12}$ abnormal flow pattern in umbilical artery was detected in 102 out of 353 (28.4\%) cases. Borowski D et al. ${ }^{13}$ detected $77.8 \%$ of abnormal S/D ratio in umbilical artery in fetuses with clinical signs of IUGR which is comparable to our findings of $81.8 \%$. Umbilical artery S/D ratio of more than three had sensitivity of $66.7 \%$, specificity of $78.85 \%$, positive predictive value $74.42 \%$ and negative predictive value of $65.08 \%$ respectively in a study by Chanprapaph et al. ${ }^{10}$ Whereas, Fleischer et al ${ }^{14}$ reported that $\mathrm{S} / \mathrm{D}$ ratio greater than 3 had a sensitivity of 78 percent in predicting IUGR. Abnormal flow pattern in umbilical artery was seen in $102(28.4 \%)$ patients in a study by Ghosh GS et al. ${ }^{12}$ Forty-four of the 134 (32.8\%) pregnancies with low birth weight had abnormal doppler velocimetry in the umbilical arteries in an Indian study by Arora et al. ${ }^{15}$ In a study conducted by Wang et al ${ }^{11}$ in high risk singleton pregnant women in China, the sensitivity, specificity and positive predictive value of umbilical arterial $\mathrm{S} / \mathrm{D}$ ratio to predict IUGR were $80.0 \%, 83.7 \%$ and $50.0 \%$. Whereas, our study showed abnormal Umbilical artery S/D ratio had a sensitivity, specificity, positive predictive value and negative predictive value of $81.8 \%, 59.2 \%, 69.2 \%$ and $74.4 \%$ respectively in diagnosing IUGR. A study was conducted by Soregaroli et a ${ }^{16}$ in 578 singleton pregnancies with diagnosis of IUGR in Italy. The mean age at delivery was 35 weeks 5 days with mean birth weight of $1.85 \mathrm{~kg}$ with $28(4.8 \%)$ intrauterine deaths, 3 elective terminations of pregnancy and 26 neonatal deaths. In our study there were 2 neonatal death and 4 still birth. Mean age of delivery was 36 weeks and 2 days with mean birth weight of $1.9 \mathrm{~kg}$ which is comparable to the study by Soregaroli et al. ${ }^{16}$

\section{CONCLUSIONS}

Doppler provides assessment of uteroplacental and fetoplacental circulation during pregnancy. It is a sensitive tool in early detection of fetal compromise and allows needful intervention. Umbilical artery doppler plays an important role in diagnosing IUGR and predicting neonatal outcome. A larger sample size with proper randomization would generate even robust findings. Routine use of doppler is highly recommended in high risk pregnancies including IUGR.

\section{REFERENCES}

1. Maulik D, Yarlagadda $P$ and Downing G. Doppler velocimetry in obstetrics. Obstet Gynecol Clin North Am 1990; 17:163-186.

2. Mari G and Piconi J. Doppler Vascular changes in IUGR, Seminars in Perinatology. 2008; 32(3):182-189.

3. Wladimiroff JW, vd Wijngaard JA, Degani S, Noordam MJ, van Eyck $\mathrm{J}$ and Tonge $\mathrm{HM}$. Cerebral and umbilical artery flow velocity waveforms in normal and growth-retarded pregnancies. Obstet Gynec 1987; 69: 705-709.

4. Nienhuis SJ, Vles JS, Gerver WJ and Hoogland HJ. Doppler ultrasonography in suspected intrauterine growth retardation: a randomized clinical trial. Ultrasound Obstet.Gynecol 1997; 9: 6-13.

5. Stearne G, Shields LE and Dubinsky TJ. Abnormal fetal cerebral and umbilical doppler measurements in fetuses with intrauterine growth restriction predicts the severity of perinatal morbidity. Journal of Clinical Ultrasound 2001; 29: 146-151.

6. Schulman H, Fleischer A, Stern W, Farmakides G, Jagani $N$ and Blattner $\mathrm{P}$. Umbilical wave ratios in human pregnancy. Am J Obstet Gynecol 1984; 148: 985-990.

7. Robert R. Intrauterine Growth Restriction. The American College of Obstetricians and Gynecologists 2002; 99: 490-496.

8. Manning FA. Intrauterine growth retardation. In: Manning FA, ed. Fetal medicine: Principles and practice. Norwalk, CT: Appleton and Lange; 1995.

9. Anshul D, Neelu S and Suneeta G. Significance of umbilical artery Doppler velocimetry in the perinatal outcome of the growth restricted fetuses. J Obstet Gynaecol of India 2010; 60:38-43.

10. Chanprapaph $P$, Tongsong $T$ and Siriaree $S$. Validity of antenatal diagnosis of intrauterine growth restriction by umbilical Doppler 
waveform index. Journal of the Medical Association of Thailand 2004; 87: 492-496.

11. Wang Z, Li W and Wang $H$. Early prediction of fetal growth retardation by umbilical and uterine arterial flow velocity systolic to diastolic ratio. Zhonghua Fu Chan Ke Za Zhi 1996; 31: 293-295.

12. Ghosh GS and Gudmundsson S. Uterine and umbilical artery Doppler are comparable in predicting perinatal outcome of growth restricted fetuses. BJOG 2009; 116: 424-430.

13. Borowski D, Czuba B and Kaczmarek P. Assessment of blood flow in the middle cerebral artery and the umbilical artery in fetuses with umbilical venous pulsations. Ginekolgia Poska.
2006; 77:190-196.

14. Fleischer A, Schulman H, Farmakides G, Bracero L, Blattner $P$ andRandolph G.Umbilicalarteryvelocitywaveformsandintrauterine growth retardation. Am J ObstetGynecol 1985; 151: 502-505.

15. Arora D, Desai SK, Sheth PN and Kania P. Significance of umbilical artery velocimetry in perinatal outcome of growth restricted fetuses. J Obstet Gynecol India 2005; 55(2): 138-143.

16. Soregaroli M, Bonera R, Danti L, Dinolfo D, Taddei F, Valcamonico A, et al. Prognostic role of umbilical artery Doppler velocimetry in growth-restricted fetuses. J Matern Fetal Neonatal Med 2002; 11: 199-203.

\section{Authors Contribution:}

GM-Concept and design of the study, literature search and review, manuscript preparation ,data collection, statistical analysis, critical revision of literature; PR-Data collection, statistical analysis, manuscript editing

\section{Work Attributed to}

Department of Radiodiagnosis and Imaging, Manipal Teaching Hospital, Pokhara, Nepal

Orcid ID:

Dr. Gyawali Merina- (1) https://orcid.org/0000-0003-1025-1869

Dr. Poudel Ramesh- (1) https://orcid.org/0000-0002-9938-0378

Source of Support: Nil, Conflict of Interest: None declared. 